\section{Uphold China's plan for cleaning water}

We disagree with aspects of Tao Tao and Kunlun Xin's plan for sustainably producing China's drinking water (Nature 511, 527-528; 2014).

In our view, the country should continue to improve its mainswater infrastructure: upgraded pipework is essential to its urbanization strategy (see X. Bai et al. Nature 509, 158-160; 2014).

Projects are already under way for recycling water and cleaning water sources. In Beijing, for example, recycled water is used in industrial processes, for replenishing rivers and lakes, and for irrigation and domestic purposes. And Yuanping city in Shanxi province now has a purification plant for industrial wastewater.

We question the feasibility of installing household water purifiers, a core feature of the authors' plan. Each would cost around 1,500 renminbi (US\$244), which amounts to 645 billion renminbi for all the families in China - much more than is needed to upgrade pipes and water-treatment plants. Doorto-door recycling of filters could prove harder to manage than centralizing purification of household water in treatment plants. Also, filters in domestic purifiers could be a health risk if not changed frequently enough.

People's reluctance to switch from traditional ways or to use poor-quality water for tasks such as laundry could also undermine the success of the proposed plans. Yanhong Tang Northeast Agricultural University, Harbin, China.

Xin Miao Harbin Institute of Technology, China. tangyanhong@aliyun.com

\section{When less means more on dairy farms}

Vanishing profit margins in dairy farming are intensifying pressure on the ubiquitous, genetically elite, high-yielding Holstein milk cow. A radical change in strategy is needed - less-intensive agriculture and a reduction in consumer wastage (see go.nature. com/bwichl) could more than compensate for lost production.

The Holstein's remarkable milk production (up to 10,000 litres a year) is associated with poor condition, fertility and survival (see P. Dillon et al. Livestock Sci.99, 141-158; 2006), and has welfare implications. Its large disease burden demands routine hormone and antibiotic treatment, despite concerns about antimicrobial resistance. During a single lactation, one cow can eat more than its own body weight in cereals, much of which is potential human food and is grown using polluting artificial fertilizer.

An alternative would be to use cattle breeds that are genetically more resilient, less diseaseprone and that have male calves suitable for beef production (females are used as milkingherd replacements). Cereal supplementation of feed may be minimized by taking advantage of the ruminant's ability to digest forage, green waste and fibrous by-products. Such a cow can still produce up to 8,000 litres of milk annually.

As the Pareto principle, or ' $80: 20$ rule', predicts, that would amount to around $80 \%$ of yield for just $20 \%$ of the environmental and welfare costs.

Mark C. Eisler, Michael R. F. Lee University of Bristol, UK. Graeme B. Martin University of Western Australia, Crawley, Australia. mark.eisler@bristol.ac.uk

\section{Private collections of fossils are a plus}

Paul Barrett and Martin Munt contend that private collections of fossil specimens hold back science because they are not readily accessible (Nature 512, 28; 2014), but this need not be the case. The solution lies in closer collaboration between private collectors and palaeontologists.

Private collectors provide a valuable service: many scientifically important specimens would never have been found, collected or prepared without their enthusiasm and dedication. This applies to every specimen of Archaeopteryx (the earliest bird) discovered so far. Public institutions, by contrast, often do not have the funds or staff to carry out essential excavations, or to acquire scientifically important specimens, which are not routinely donated.

Thanks to the cooperation of private collectors, such specimens can be well described and documented (using computed tomography scanning, for example). This is preferable to overlooking scientifically important data, even if access is subsequently limited.

We agree that specimens should be housed in conditions that allow verification of earlier observations. But this is not always the case for specimens held in public institutions: in our experience, access to material is sometimes denied, specimens may be lost or destroyed, or exhibited in such a way as to make detailed study difficult.

Oliver W. M. Rauhut, Adriana López-Arbarello, Gert Wörheide Bavarian State Collection for Palaeontology and Geology; and Ludwig-Maximilians University of Munich, Germany. o.rauhut@lrz.uni-muenchen.de

\section{Japan to learn from biomedical cases}

The recent spate of high-profile retractions of biomedical papers by Japanese scientists is undermining the push by Japan's prime minister, Shinzo Abe, to strengthen medical research and innovation in the country (see go.nature.com/cznkrb). To stem this apparent proliferation of research misconduct, we suggest that Abe's government needs to reform relations between Japan's pharmaceutical industry and its health and medical community.

Several cases have involved medical schools that receive unrestricted funding from big Japanese drug companies. These include the Jikei Heart Study, in which data manipulation was implicated in the clinical trial of a blood-pressure drug (see Lancet 382, 843; 2013); the questionable procurement of patient data for a leukaemia drug by company employees (see J. McCurry Lancet 383, 2111; 2014); and criticisms of data handling in a large government-supported study on Alzheimer's disease (see D. Normile Science 345, 17; 2014).

There is also the infamous case of more than 100 papers by a Japanese anaesthesiologist that are now in the process of being retracted (see Nature 489, 346-347; 2012).

These worrying examples may be symptomatic of a deeper malady. As well as being under pressure to publish, biomedical researchers in Japan are having to rely increasingly on large donations from the pharmaceutical industry as government funding shrinks.

The prime minister's 'Abenomics' strategy for better health care requires a global, fair and competitive yet collaborative environment and partnership among stakeholders. It is therefore imperative that investigations into misconduct allegations are openly and formally conducted and that the lessons learned are used to limit further cases.

Tetsuya Tanimoto, Masahiro Kami, Kenji Shibuya University of Tokyo, Japan. tetanimot@yahoo.co.jp

\section{CONTRIBUTIONS}

Correspondence may be submitted to correspondence@nature. com after consulting the guidelines at http:// go.nature.com/cmchno. 